\title{
Cholesterol Crystal Measurement
}

National Cancer Institute

\section{Source}

National Cancer Institute. Cholesterol Crystal Measurement. NCI Thesaurus. Code C74672.

The determination of the amount of cholesterol crystals present in a sample. 